\title{
A strong Lewis acid imparts high ionic conductivity and interfacial stability to polymer composite electrolytes towards all-solid-state Li-metal batteries
}

\author{
Litong Wang ${ }^{1}$, Yunlei Zhong ${ }^{1}$, Zhaorui Wen ${ }^{1}$, Chaowei $\mathrm{Li}^{1}$, Jingxin Zhao ${ }^{1}$, Mingzheng $\mathrm{Ge}^{1,4}$, \\ Pengfei Zhou ${ }^{1}$, Yanyan Zhang ${ }^{2}$, Yuxin Tang ${ }^{2 *}$ and Guo Hong ${ }^{1,3^{*}}$
}

\begin{abstract}
The development of high-performance solid polymer electrolytes is crucial for producing all-solid-state lithium metal batteries with high safety and high energy density. However, the low ionic conductivity of solid polymer electrolytes and their unstable electrolyte/electrode interfaces have hindered their widespread utilization. To address these critical challenges, a strong Lewis acid (aluminum fluoride $\left(\mathrm{AlF}_{3}\right)$ ) with dual functionality is introduced into poly(ethylene oxide) (PEO)-based polymer electrolyte. The $\mathrm{AlF}_{3}$ facilitates the dissociation of lithium salt, increasing the iontransfer efficiency due to the Lewis acid-base interaction; further the in-situ formation of lithium fluoride-rich interfacial layer is promoted, which suppresses the uneven lithium deposition and continuous undesired reactions between the $\mathrm{Li}$ metal and PEO matrix. Benefiting from our rational design, the symmetric $\mathrm{Li} / \mathrm{Li}$ battery with the modified electrolyte exhibits much longer cycling stability (over $3600 \mathrm{~h}$ ) than that of the pure $\mathrm{PEO} /$ lithium bis(trifluoromethanesulfonyl)imide (LiTFSI) electrolyte $(550 \mathrm{~h})$. Furthermore, the all-solid-state $\mathrm{LiFePO}_{4}$ full cell with the composite electrolyte displays a much higher Coulombic efficiency (98.4\% after 150 cycles) than that of the electrolyte without the $\mathrm{AlF}_{3}$ additive $(63.3 \%$ after 150 cycles) at a large voltage window of 2.4-4.2 V, demonstrating the improved interface and cycling stability of solid polymer lithium metal batteries.
\end{abstract}

Keywords: all-solid-state battery, composite electrolyte, interfaces, Li-ion conductivity, polyethylene oxide

\section{INTRODUCTION}

The development of solid-state lithium metal batteries weeding out flammable liquid organic electrolytes is considered to be a promising solution to meet the demands for safety and energy density in next-generation energy storage devices [1,2]. In addition to their non-flammable nature, solid-state electrolytes with high thermal stability and mechanical strength can mitigate the safety issues and eliminate the need for dynamic security monitoring systems associated with liquid batteries [3]. Currently, the commercial graphite anode $\left(372 \mathrm{~mA} \mathrm{~h} \mathrm{~g}^{-1}\right)$ used in lithium-ion batteries is approaching its energy density limit of $770 \mathrm{~W} \mathrm{~h} \mathrm{~L}^{-1}$ and $260 \mathrm{~W} \mathrm{~h} \mathrm{~kg}^{-1}[4,5]$. Solid electrolytes make it possible to directly use lithium metal anodes $\left(3860 \mathrm{~mA} \mathrm{~h} \mathrm{~g}^{-1}\right)$ and obtain a much higher energy density. Several types of solid electrolytes have been proposed and widely investigated, including oxides, sulfides, halides, and polymers [6-10]. Among the various solid electrolytes, the polymer electrolytes are particularly attractive due to their excellent mechanical properties, good workability, and scalability for the current lithium-ion systems [11-13].

Solid polymer electrolytes generally comprise an ionic-conductive polymer matrix and lithium salts, where the lithium ions can be solvated by intermolecular interactions. Lithium-ion diffusion in polymer electrolytes is mediated by the hopping of lithium ions coupled with the local segment motion in the amorphous region [14]. The complex of poly(ethylene oxide) (PEO) polymer matrix with lithium bis(trifluoro methanesulfonyl)imide (LiTFSI) is one of the most practical and widely studied systems for solid polymer electrolytes owing to their numerous advantages in terms of excellent solvation ability for lithium salts, acceptable mechanical stability, and low gravimetric density [15]. Nevertheless, PEO-based electrolytes still suffer from low ion transference efficiency, severe parasitic reactions with Li metal (Fig. 1a), and limited oxidation potentials (less than $4.0 \mathrm{~V}$ ). To date, a considerable amount of studies have been devoted to addressing such issues and improving the electrochemical performance of PEO-based polymer electrolytes, such as new lithium salt design [16], blending with other polymers, and the use of additional inorganic fillers $[17,18]$. Among them, introducing ceramic fillers into the polymer matrix is widely reported to enhance the ionic conductivity, through which the amorphous region can be enriched by the physical/chemical interaction between the polymer chains and the fillers $[19,20]$. Nevertheless, the unstable lithium/polymer interface, including the formation of Li dendrites and severe side reactions, still hinders the cycling stability [21,22].

\footnotetext{
${ }^{1}$ Institute of Applied Physics and Materials Engineering, University of Macau, Avenida da Universidade, Taipa, Macau SAR 999078, China

${ }^{2}$ College of Chemical Engineering, Fuzhou University, Fuzhou 350116, China

${ }^{3}$ Department of Physics and Chemistry, Faculty of Science and Technology, University of Macau, Avenida da Universidade, Taipa, Macau SAR 999078, China

${ }^{4}$ School of Textile and Clothing, Nantong University, Nantong 226019, China

* Corresponding authors (emails: yxtang@fzu.edu.cn (Tang Y); ghong@um.edu.mo (Hong G))
} 

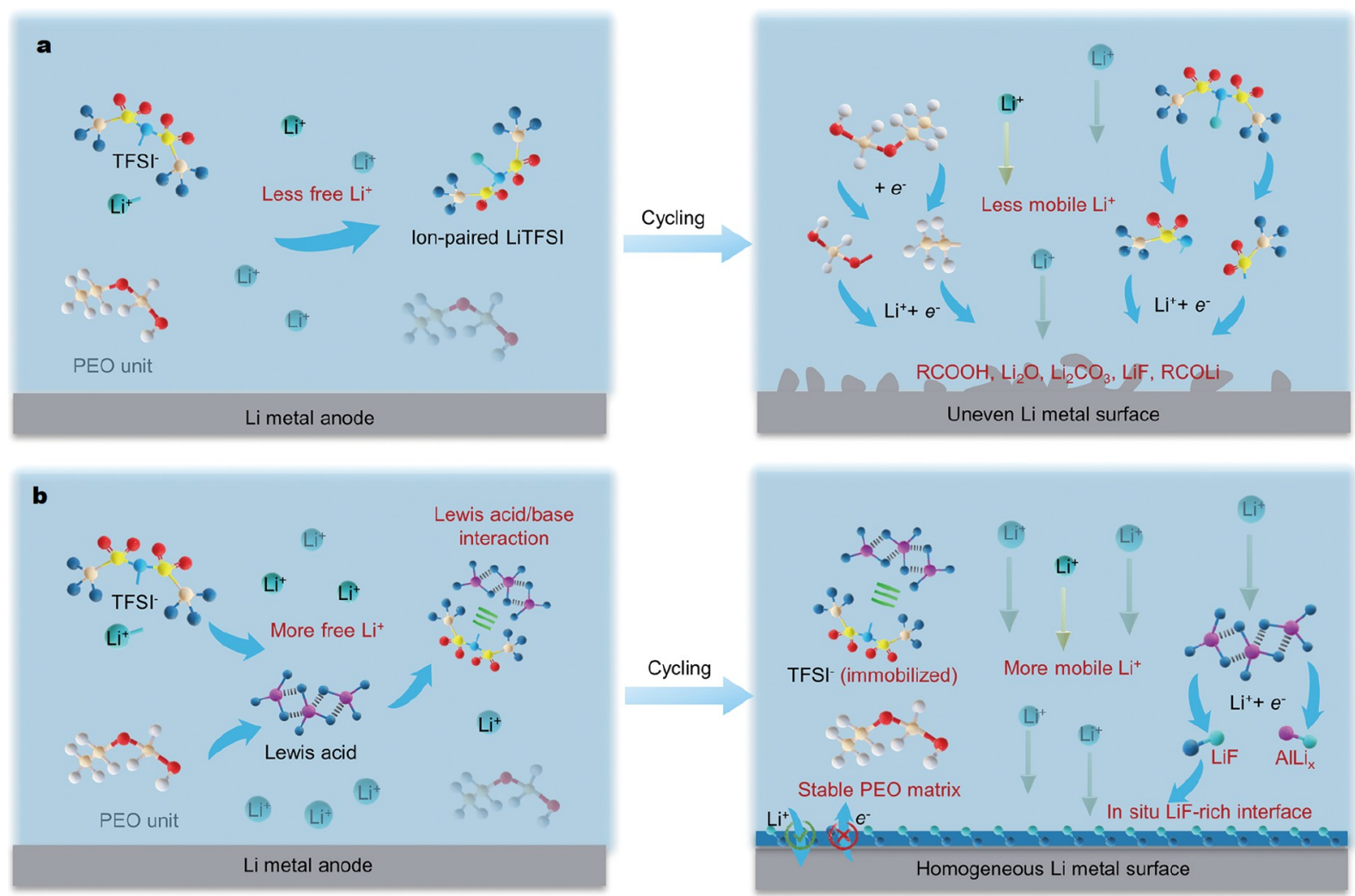

Figure 1 Illustration of the design strategy for the PEO-based composite electrolyte: (a) the traditional PEO/LiTFSI electrolyte with an unstable interface induced by the undesirable reactions; (b) our rational design of the Lewis acid-PEO/LiTFSI composite electrolyte with high ionic conductivity and a LiF-rich interface.

To address the aforementioned challenges affecting PEObased electrolytes, we introduce a strong Lewis acid, $\mathrm{AlF}_{3}$, into PEO for the first time to increase the ion transport kinetics and improve interface stability of the PEO-based electrolyte in allsolid-state Li-metal batteries. In particular, the Lewis acid-base interaction between $\mathrm{AlF}_{3}$ and $\mathrm{TFSI}^{-}$facilitates the dissociation of Li salt and increases the concentration of free Li-ions, while the LiF-enriched interfacial layer is in-situ generated during the initial cycling, facilitating the homogeneous lithium ion deposition and inhibiting the undesired reactions between lithium and the PEO matrix (Fig. 1b). Both symmetric Li/Li and all-solid-state $\mathrm{LiFePO}_{4} / \mathrm{Li}$ full cells with the modified solid electrolyte demonstrate significant improvements in cycling stability and electrochemical performance. Our work highlights the mechanism for the construction of stable composite electrolytes by increasing ion mobility and stabilizing the Li/PEO interface.

\section{RESULTS AND DISCUSSION}

\section{Structural characterization and kinetics of the PEO-based composite electrolytes}

The fabrication diagram of PEO/LiTFSI polymer electrolyte membranes blended with $\mathrm{AlF}_{3}$ is given in Fig. S1. Firstly, the micro-sized $\mathrm{AlF}_{3}$ particles with diameters of approximately $30-40 \mu \mathrm{m}$ (Fig. S2) were introduced into the PEO/LiTFSI system, which was further confirmed by X-ray diffraction (XRD) and X-ray photoelectron spectroscopy (XPS, Fig. S3). Subsequently, $\mathrm{AlF}_{3}$ was partially dissolved in acetonitrile $(\mathrm{ACN})$ and the apparent size of the undissolved $\mathrm{AlF}_{3}$ was reduced to the nanoscale $(100-200 \mathrm{~nm})$. The decreased nanoscale fillers generally had more interfacial ion transport paths for improving the ion conductivity [23,24]. The detailed morphology of the surface and cross-section of the as-obtained composite electrolyte is shown in Fig. S4. The cross-section scanning electron microscopy (SEM) image shows that the dense membrane has a thickness of around $110 \mu \mathrm{m}$ (Fig. S4b). The composite membrane exhibits a smooth surface (Fig. S4c, d), and the energy dispersive spectrometer (EDS) mapping images show that both the $\mathrm{Al}$ and the $\mathrm{F}$ elements have a uniform distribution (Fig. S4c, d).

The structure and crystallinity of the as-fabricated PEO composite electrolytes with various amounts of $\mathrm{AlF}_{3}$ additive were determined by XRD, as shown in Fig. 2a and Fig. S5. The soft PEO matrix acted as the critical ingredient in the electrolyte. Several intense and strong peaks in the XRD pattern indicate a high crystallinity at room temperature. The XRD analysis of $\mathrm{PEO} / \mathrm{LiTFSI}$ suggests that the crystallinity reduced with the addition of LiTFSI salts in the PEO matrix, which was attributed to the effect of the formation of ion-dipole complexes on the ordered arrangement of the PEO chains and the enhancement of the amorphous content $[25,26]$. For the PEO/LiTFSI $+x$ wt $\%$ $\mathrm{AlF}_{3}(x=2,5,8,12,15,20,30)$ composite electrolytes, the intensity of the PEO/LiTFSI peaks gradually decreased, while the intensity of the $\mathrm{AlF}_{3}$ peak gradually increased. Furthermore, the weakened intensity of the PEO matrix can be attributed to the disruptive effect of $\mathrm{AlF}_{3}$ on the ordered arrangement of the polymer chains, which also promoted the increase in the amorphous phase [27]. The weakened characteristic peaks of $\mathrm{PEO}$ with more amorphous regions can wrap the $\mathrm{TFSI}^{-}$anions 

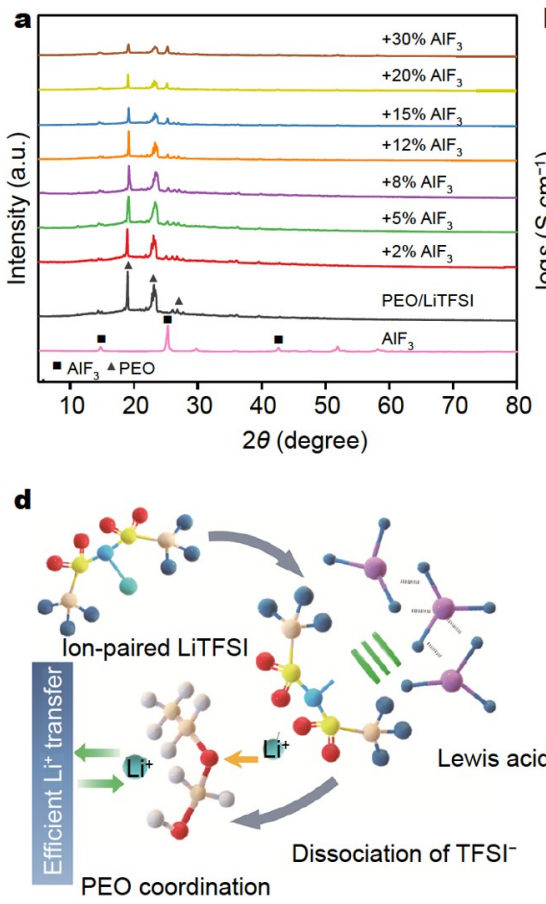
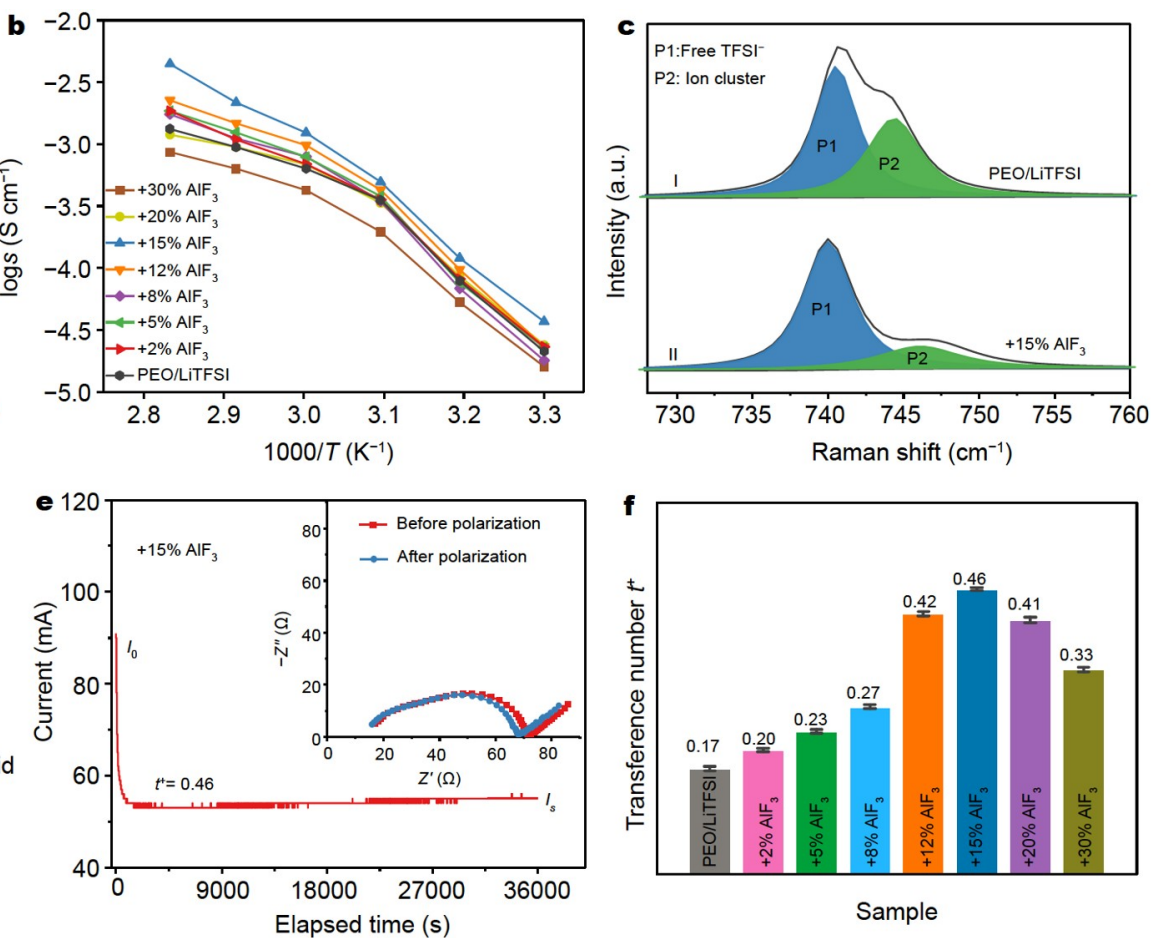

Figure 2 (a) XRD patterns of pure PEO/LiTFSI, $\mathrm{AlF}_{3}$, and the composite electrolytes with various amounts of $\mathrm{AlF}_{3}$. (b) Arrhenius plots of the composite membranes with varying weight percentages (wt\%) of $\mathrm{AlF}_{3}$. (c) Raman spectra of pure PEO/LiTFSI and PEO/LiTFSI + 15\% AlF 3 membranes, fitted with the P1 and P2 bands. (d) Schematic representation of the proposed mechanism for the promotion of ion-paired LiTFSI dissociation by the Lewis acid. (e) Chronoamperometry curves of $\mathrm{Li}\left|\mathrm{PEO} / \mathrm{LiTFSI}+15 \% \mathrm{AlF}_{3}\right| \mathrm{Li}$ cell at a potential of $10 \mathrm{mV}$. The inset shows the EIS spectra before and after polarization. (f) Comparison of ion transference numbers of the PEO/LiTFSI electrolyte and composite electrolytes with various amounts of AlF 3 .

and induce high ionic conductivity of the composite electrolyte [28].

The ionic conductivity of the polymer-based electrolyte is regarded as a key requirement for practical applications, which is affected by polymer chain segmental motion and hopping in the amorphous phase. The temperature-dependent ionic conductivities of PEO/LiTFSI $+x$ wt $\% \mathrm{AlF}_{3}$ composite electrolytes were evaluated by electrochemical impedance spectroscopy (EIS, Fig. S6) [29,30]. Fig. 2b depicts the temperature dependence (from 30 to $80^{\circ} \mathrm{C}$ ) of the ionic conductivities for the composite electrolyte, along with the corresponding Arrhenius plot. With the increase of temperature, the ionic conductivity of all electrolytes increased due to the improved movement of PEO segments. The detailed temperature conductivities of composite electrolytes with varying amounts of $\mathrm{AlF}_{3}$ are plotted in Fig. S7. It is also worth noting that the PEO/LiTFSI $+15 \% \mathrm{AlF}_{3}$ composite electrolyte had a preferable ionic conductivity of $1.2 \times$ $10^{-3} \mathrm{~S} \mathrm{~cm}^{-1}$ at $60^{\circ} \mathrm{C}$, whereas pure PEO/LiTFSI exhibited a conductivity of $6.2 \times 10^{-4} \mathrm{~S} \mathrm{~cm}^{-1}$. Further, the conductivity of the $\mathrm{PEO} / \mathrm{LiTFSI}+15 \% \mathrm{AlF}_{3}$ composite electrolyte approached $3.7 \times 10^{-5} \mathrm{~S} \mathrm{~cm}^{-1}$ at $25^{\circ} \mathrm{C}$, which was higher than that of $\mathrm{PEO} /$ LiTFSI $\left(2.2 \times 10^{-5} \mathrm{~S} \mathrm{~cm}^{-1}\right)$. The PEO/LiTFSI $+15 \% \mathrm{AlF}_{3}$ electrolyte demonstrated an obvious improvement in terms of ionic conductivity, which was attributed to the increased amorphous region. In addition, the fast ion-conducting pathways on the interface could be another reason for the favorable electrochemical features. The much higher concentrations of ions diluted the polymer electrolyte and blocked the ion transfer channel in the polymer matrix, inducing a decreased ionic conductivity. Therefore, the optimized composition was PEO/
LiTFSI $+15 \% \mathrm{AlF}_{3}$.

Raman spectroscopy was conducted to confirm the presence of ion-PEO-AlF $\mathrm{A}_{3}$ interactions, along with the conformation isomerism of $\mathrm{TFSI}^{-}$anions. The Raman spectra of PEO/LiTFSI and PEO/LiTFSI $+15 \% \mathrm{AlF}_{3}$ are shown in Fig. $2 \mathrm{c}$. The two fitted Lorentzian peaks, located at $741 \mathrm{~cm}^{-1}(\mathrm{P} 1)$ and $747 \mathrm{~cm}^{-1}(\mathrm{P} 2)$, correspond to the dissociated $\mathrm{TFSI}^{-}$anions and the anionic cluster $\left[\mathrm{Li}(\mathrm{TFSI})_{2}\right]^{-}$, respectively $[31,32]$. The lower anionic cluster $\left[\mathrm{Li}(\mathrm{TFSI})_{2}\right]^{-}$content indicates more free $\mathrm{Li}^{+}$coordinated with ether oxygen atoms on the PEO chains, causing inefficient ion transport in the polymer matrix. The spectrum of the $\mathrm{PEO} /$ LiTFSI $+15 \% \mathrm{AlF}_{3}$ membrane demonstrates a strong $\mathrm{P} 1$ band and a relatively weak $\mathrm{P} 2$ band, proving the existence of more free TFSI $^{-}$. Furthermore, the percentage of free TFSI ${ }^{-}$anions can be calculated using the following equation:

$\left[\right.$ free $\left.\mathrm{TFSI}^{-}\right]=\frac{A(\mathrm{P} 1)}{A(\mathrm{P} 1+\mathrm{P} 2)} \times 100 \%$,

where $A(\mathrm{P} 1)$ and $A(\mathrm{P} 2)$ represent the intensity of the $\mathrm{P} 1$ and $\mathrm{P} 2$ bands, respectively. The percentage of free $\mathrm{TFSI}^{-}$anions in the $\mathrm{PEO} / \mathrm{LiTFSI}+15 \% \mathrm{AlF}_{3}$ system is $85.6 \%$, which is much higher than that of pure PEO/LiTFSI (43.2\% without $\mathrm{AlF}_{3}$ ). This result demonstrates the better dissociation of ion clusters in the composite electrolyte.

In addition to the ionic conductivity, the ion transference number $\left(t^{+}\right)$is another crucial parameter that determines the performance of electrolytes and can be used to calculate the contribution of Li-ion transport. In accordance with the Lewis acid/base theory, the heterostructure inorganic Lewis acid $\mathrm{AlF}_{3}$ can bond with the TFSI ${ }^{-}$by sharing an electron pair. $\mathrm{F}$ is the 
most electronegative element. Owing to the large energy difference between the $2 \mathrm{p}$ orbitals of $\mathrm{F}$ and the empty $3 \mathrm{~d}$ orbitals of $\mathrm{Al}$, the $\mathrm{Al}$ atom can accept electrons. Hence, $\mathrm{AlF}_{3}$ is more highly Lewis acidic and has a greater tendency than $\mathrm{Li}^{+}$to accept a pair of electrons. Therefore, the affinity between the surfaces of $\mathrm{AlF}_{3}$ fillers and anions facilitates the immobilization of $\mathrm{TFSI}^{-}$and a higher ion transference number (Fig. 2d). In particular, Fig. 2e shows the current change during the direct current (DC) polarization process, with the inset showing the EIS spectra of the initial and final state. In addition to the relatively high ionic conductivity, the PEO/LiTFSI $+15 \% \mathrm{AlF}_{3}$ composite electrolyte also demonstrates a high $\mathrm{Li}^{+}$transference number $(0.46)$, which is 1.70 times higher than that of PEO/LiTFSI (0.17, Fig. S8) without any rigid filler. This is consistent with the interaction between the $\mathrm{AlF}_{3}$ Lewis acid and $\mathrm{TFSI}^{-}$. Furthermore, increasing the $\mathrm{AlF}_{3}$ load was found to increase the transference number; there was an optimal value (15\%) found in this study. Excess amounts of $\mathrm{AlF}_{3}$ led to a decreased transference number and limited the ion transfer in the polymer (Fig. 1f), which corresponded with the ion conductivity results and the percolation model. The increased $\mathrm{Li}^{+}$transference number and ion conductivity indicate that moderate amounts of $\mathrm{AlF}_{3}$ can reduce the interaction between $\mathrm{Li}^{+}$and $\mathrm{TFSI}^{-}$, increase the free $\mathrm{Li}^{+}$concentration, and immobilize anions. The high Li-ion transference number demonstrates the efficient transmission of $\mathrm{Li}$ ions, which could reduce the negative effects of space charge on the interface between the electrolyte and electrode [18]. Thus, the $\mathrm{PEO} / \mathrm{LiTFSI}+15 \% \mathrm{AlF}_{3}$ composite electrolyte, with a higher ion transference number, is expected to suppress lithium dendrite proliferation in working batteries $[33,34]$.

Stability of the composite electrolyte contacting Li metal anode The electrochemical compatibility and stability of the composite electrolyte with a metallic $\mathrm{Li}$ anode were evaluated using symmetric $\mathrm{Li} \mid \mathrm{Li}$ cells. The $\mathrm{PEO} / \mathrm{LiTFSI}+15 \% \mathrm{AlF}_{3}$ composite electrolyte was sandwiched between two identical $\mathrm{Li}$ anodes to simulate practical Li stripping/plating behavior. Fig. 3a shows the rate performance and long-term cycling stability at various current densities at the deposition capacity of $0.2 \mathrm{~mA} \mathrm{~h} \mathrm{~cm}$. For comparison, the pure PEO/LiTFSI membrane was also tested. Firstly, it was found that the overpotential of cells with the composite electrolyte increased slightly, from 32 to $131 \mathrm{mV}$, along with an increase in the current density from 0.1 to $0.5 \mathrm{~mA} \mathrm{~cm}^{-2}$, suggesting an excellent rate performance and high

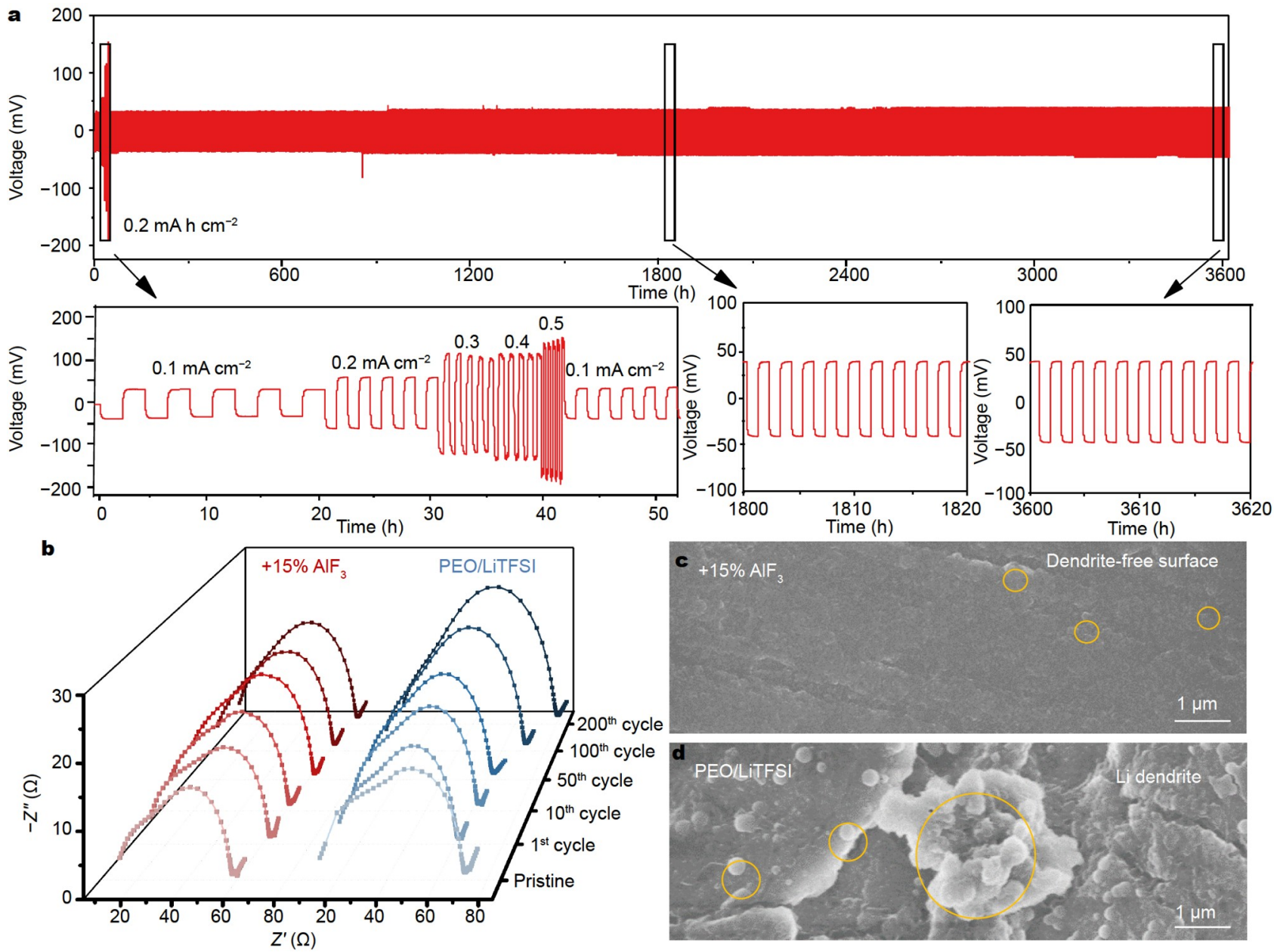

Figure 3 (a) Galvanostatic cycling and rate voltage profiles of symmetrical cells with PEO/LiTFSI $+15 \% \mathrm{AlF}_{3}$ electrolytes under current densities of $0.1,0.2$, $0.3,0.4$ and $0.5 \mathrm{~mA} \mathrm{~cm}^{-2}$ with a fixed capacity of $0.2 \mathrm{~mA} \mathrm{~h} \mathrm{~cm}^{-2}$. (b) Nyquist plots of the impedance spectra of symmetric cells using PEO/LiTFSI $+15 \%$ AlF 3 electrolytes and PEO/LiTFSI after various numbers of cycles at a current density of $0.1 \mathrm{~mA} \mathrm{~cm}{ }^{-2}$ at $60^{\circ} \mathrm{C}$. Comparison of the surface SEM images of Li metal after 200 cycles contacted with (c) PEO/LiTFSI $+15 \% \mathrm{AlF}_{3}$ electrolytes and (d) PEO/LiTFSI electrolytes. 
interface stability with metallic Li. It should be noted that the sudden drops of overpotential during long periods of cycling could be attributed to the temperature decrease caused by opening the test incubator since the ionic conductivity of the PEO-based electrolyte increases with temperature. Therefore, the overvoltage returned to normal after the temperature reverted to the test point. In comparison, it is apparent from Fig. S9 that the cell based on pure PEO/LiTFSI exhibits a higher overpotential $(50 \mathrm{mV})$ at $0.1 \mathrm{~mA} \mathrm{~cm}{ }^{-2}$ and could not run well at higher current densities, which is probably caused by the dendrite growth and short-circuiting. The symmetric cell assembled with the composite electrolyte demonstrates ultra-long cycle stability with negligibly increased voltage polarizations over $3600 \mathrm{~h}$. The cell without $\mathrm{AlF}_{3}$ has a higher overpotential and much shorter lifespan (550 h, Fig. S10), which is induced by the uneven Li deposition and continued deterioration of the interface. The improved electrochemical performance afforded by $\mathrm{AlF}_{3}$ additives can be attributed to the enhanced ionic conductivity and ion transference number [35].

To further understand the fundamental mechanism affecting the stability of the interface of the composite electrolyte with metallic lithium, impedance measurement was performed and tracked after cycling for 1, 10, 50, 100, and 200 cycles (Fig. 3b). The semicircles of the Nyquist plots in the high-frequency region indicate the charge-transfer resistance on the electrode/ electrolyte interface. The interfacial resistance can be obtained by fitting the Nyquist plots using the equivalent circuit depicted in Fig. S11. After initial cycling, the symmetric Li||Li cell with the composite electrolyte exhibited a lower interface impedance of $55 \Omega$ which is lower than that of the electrolyte without any rigid fillers $(62 \Omega)$. This could be attributed to the improved interface contact. Further, the impedance of the PEO/LiTFSI electrolyte increased obviously after 200 cycles. The increased impendence could have been induced by the continuous side reactions on the interface of Li metal/electrolyte, which destroy the previously generated solid electrolyte interphase (SEI) [36], leading to a thickened and uneven Li/PEO interface. In comparison, the $\mathrm{PEO} / \mathrm{LiTFSI}+15 \% \mathrm{AlF}_{3}$ composite demonstrated fewer impedance changes and stabilized at around $62 \Omega$. The $\mathrm{AlF}_{3}$ additive was partially insoluble in the composite electrolyte, which led to a relatively stable SEI and inhibited the continuation of side reactions, enhancing the interface stability.

To visually analyze the influence of the PEO/LiTFSI $+15 \%$ $\mathrm{AlF}_{3}$ composite electrolyte on the $\mathrm{Li}$ deposition, the surface morphologies of the electrolyte and Li metal anode after cycling were determined, as shown in Fig. 3c, d and Fig. S12. In comparison to the pristine Li metal before cycling (Fig. S13), the Li surface contacting the composite electrolyte (Fig. 3c) demonstrated a smooth surface and a few bumps after 200 cycles. In contrast, micro-sized $\mathrm{Li}$ particles and dendrites were found on the $\mathrm{Li}$ surface contacting the pure PEO/LiTFSI electrolyte. Simultaneously, as shown in Fig. S12, small wrinkles and fractures appeared on the cycled surface of the PEO/LiTFSI electrolyte. Once the dendrites keep growing along with the cracks, short-circuiting will occur. The smooth surface morphology in the presence of the composite electrolyte is consistent with the effect of $\mathrm{Li}$ metal and the rigid additive is effective for dendrite inhibition [37]. Further, as demonstrated in Fig. S14, compared with the pure PEO/LiTFSI electrolyte, the mechanical strength of the composite electrolytes increased from 0.98 to $1.94 \mathrm{MPa}$, making it possible to hinder the propagation of Li dendrites [38].
Therefore, the PEO/LiTFSI electrolyte modified by $\mathrm{AlF}_{3}$ not only contributes to the improvement of the rigidity of the electrolyte membrane, but also enhances the Li-ion transfer efficiency, which could lead to a homogeneous ion distribution and inhibit the puncturing of the electrolyte by $\mathrm{Li}$ dendrites.

\section{Evolution mechanism of the composite electrolyte/metallic $\mathrm{Li}$ interface}

Furthermore, the evolution mechanism of the electrolyte interface composition was detected using XPS. The pristine and cycled detailed spectra of C 1s, F 1s, Li 1s, S 2p, N 1s, and O 1s signals of the PEO/LiTFSI and PEO/LiTFSI $+15 \% \mathrm{AlF}_{3}$ are shown in Fig. 4, Figs S15 and S16. Firstly, the binding energy scale of both the survey scan and narrow spectra were calibrated by the $\mathrm{C} 1 \mathrm{~s}$ signal of aliphatic carbon $(284.8 \mathrm{eV})$. Fig. 4 shows the $\mathrm{C} 1 \mathrm{~s}$ and $\mathrm{F} 1 \mathrm{~s}$ spectra from the outermost surface of the two electrolyte systems. As demonstrated in Fig. 4a, the peaks of the pristine composite electrolyte at $286.7 \mathrm{eV}$ show a lower content of $\mathrm{C}-\mathrm{O}-\mathrm{C}$ with the addition of $\mathrm{AlF}_{3}$. This result corroborates the implication from the $\mathrm{XRD}$ graphs that the crystalline volume in the PEO matrix decreases with the addition of $\mathrm{AlF}_{3}$ [39]. Furthermore, the new peaks at $290.9 \mathrm{eV}$ on both surfaces of cycled electrolytes can be attributed to ROOLi, which is associated with the decomposition of PEO [40,41]. However, the C 1s spectral evolution indicates that the cycled electrolyte without $\mathrm{AlF}_{3}$ modification has an obvious decline of the $\mathrm{C}-\mathrm{O}(286.7 \mathrm{eV})$ configuration, which is induced by the undesired side reactions between metallic $\mathrm{Li}$ and the PEO matrix. Considering the ultrahigh thermodynamic instability of Li metal, severe degradation of $\mathrm{PEO}$ to generate $\mathrm{C}_{2} \mathrm{H}_{2}, \mathrm{H}_{2}$, and alkoxide species occurred at the Li/PEO interface. Furthermore, during the repeated $\mathrm{Li}$ metal plating/stripping process, continuous side reactions caused the deterioration of the interface. In contrast, the composite electrolyte demonstrated no obvious decreases in $\mathrm{C}-\mathrm{O}$ bonding, which reconfirmed that the $\mathrm{AlF}_{3}$ in the composite electrolyte could suppress the Li dendrite growth and the continuous generation of fresh interfaces, improving the stability of the Li/electrolyte interface.

The fitted high-resolution XPS spectra of F 1s for the pristine and cycled specimens are given in Fig. $4 \mathrm{~b}$. There was a unique peak on the initial surface of the composite electrolyte, which can be attributed to the presence of $\mathrm{AlF}_{3}(685.8 \mathrm{eV})$. Interestingly, it shifted to lower binding energy $(684.8 \mathrm{eV})$ after cycling, demonstrating that the $\mathrm{AlF}_{3}$ had reacted with $\mathrm{Li}$ metal and transformed into LiF [42-44]. Furthermore, in comparison with the pure PEO/LiTFSI electrolyte, the cycled composite electrolyte exhibited an increased generation of $\mathrm{LiF}$ on the surface. $\mathrm{LiF}$ was recognized for its ability to inhibit dendrite growth and its existence had been widely verified to stabilize the Li/electrolyte interface [45-47]. As all the LiF generated in the subsequent cycling process comes from the decomposition of the $\mathrm{TFSI}^{-}$, it can be inferred that more fresh interfaces had been generated in the pure PEO electrolytes. Owing to the in-situ generated LiF interface during the initial cycling, the composite electrolyte with $\mathrm{AlF}_{3}$ additive can inhibit the continuous side reactions between metallic Li and the PEO matrix. Similar results can be found in the spectrum of Li 1s, which is shown in Fig. S16. The Li 1s peak of the cycled composite surface had a stronger intensity than the pristine surface, indicating the formation of $\mathrm{LiF}$ and other compounds. Further, the Li-containing compounds of $\mathrm{Li}_{2} \mathrm{SO}_{3}, \mathrm{LiN}_{3}$, and ROLi were detected on the cycled 

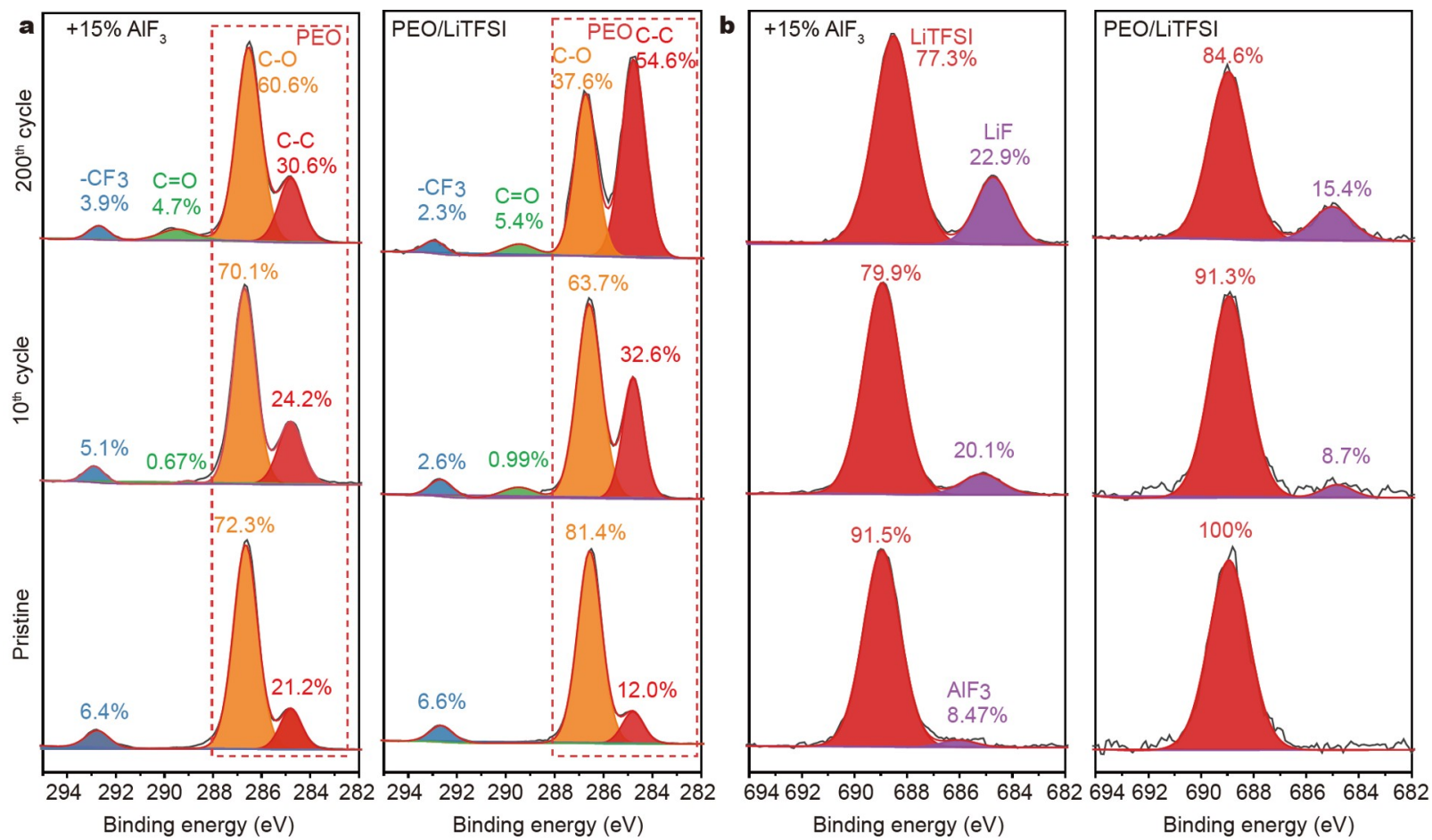

Figure 4 High-resolution spectra of (a) C 1s and (b) F 1s of the pristine and cycled PEO/LiTFSI and PEO/LiTFSI $+15 \%$ AlF 3 electrolytes, demonstrating better polymer matrix stability and more LiF generation of the hybrid electrolyte after cycling.

electrolyte surface, which were also beneficial to stabilizing the metallic lithium/electrolyte interface.

To further determine the evolution mechanism of the composite electrolyte/Li interface, the morphologies and XPS depth profiles of the cycled Li metal anode were investigated (Fig. 5). As demonstrated in Fig. 5a, certain amounts of $\mathrm{F}$ and $\mathrm{Al}$ were evenly distributed on the surface of the cycled Li metal anode, suggesting that a conversion reaction of $\mathrm{AlF}_{3}$ occurred during the cycling, as follows: $\mathrm{AlF}_{3}+\mathrm{Li} \rightarrow \mathrm{AlLi}_{x}+\mathrm{LiF}$. As expected, the metallic AlLi $i_{x}$ alloy was detected by the XPS spectrum after the cycling (Fig. S17), which corroborated the implication from the SEM images that there were reactions between the metallic $\mathrm{Li}$ and $\mathrm{AlF}_{3}$. In addition, the detailed compositions of the cycled $\mathrm{Li}$ metal surface contacting the pure and composite electrolytes were investigated using the XPS depth profiles (Fig. 5b-d). The Li 1s spectrum demonstrated a single peak, and LiF constitutes a large portion of the whole [48]. With increases in the etching time, the peak shifted to lower binding energy and became more apparent, indicating baseline XPS spectra for RCOO- $\mathrm{Li}$ and $\mathrm{Li}^{0}$ (Fig. 5b). The fitted detailed C and F XPS spectra of the cycled Li metal were consistent with the results of those contacting the pure and composite electrolytes. As demonstrated in Fig. 5c, the intensity of the $-\mathrm{CF}_{3}$ in LiTFSI and PEO peaks significantly decreased, which was consistent with the results for Li 1s [49]. In contrast, the signals of $\mathrm{C} 1 \mathrm{~s}$ in Li metal contacting the $\mathrm{PEO} /$ LiTFSI electrolyte without $\mathrm{AlF}_{3}$ exhibited a sharp decline, which was consistent with the surface of the PEO/LiTFSI electrolyte. This was likely caused by the undesirable reactions between the $\mathrm{Li}$ metal and $\mathrm{PEO}$ membrane. Further, the $-\mathrm{O}-\mathrm{C}=\mathrm{O}$ signal, related to the formation of RCOO-Li of the PEO/LiTFSI electrolyte without $\mathrm{AlF}_{3}$, became more apparent after sputtering, indicating a much more passive layer on the Li metal surface. The fitted F XPS spectrum also exhibited two peaks, and the content of LiF was dominant after etching (Fig. 5d). In comparison with the membrane without $\mathrm{AlF}_{3}$, there was more $\mathrm{F}$ content in the interface layer of the $\mathrm{Li}$ metal contacting the composite electrolyte, indicating the formation of a LiF-riched interfacial layer on the Li metal surface. In addition, it should be noted that the LiF was mainly concentrated near the surface of the Li metal, which was the origin of the improvement in interface stability and the prolonged cycling life of symmetrical cells containing the composite electrolytes.

To better illustrate the mechanism of $\mathrm{AlF}_{3}$ for stabilizing the $\mathrm{Li} / \mathrm{PEO}$ interface, the Li-ion transfer behavior in both electrolytes was compared, as shown in Fig. S18. Particularly, three main contributions of $\mathrm{AlF}_{3}$ additives can be summarized from the results described above. First, the Lewis acid-base interaction between $\mathrm{AlF}_{3}$ and $\mathrm{TFSI}^{-}$facilitated the dissociation of $\mathrm{Li}$ salt and immobilized the anions, lowering the interface polarization. Second, the rigid additive effectively increased the amorphous volume of the PEO matrix and improved the amount of free $\mathrm{Li}$, which could enhance Li-ion conduction. Third, the in-situ generated LiF-rich interface during the initial cycling could inhibit the continuous side reactions between metallic $\mathrm{Li}$ and the PEO matrix, enhancing the stability of the $\mathrm{Li} / \mathrm{PEO}$ interface.

\section{All-solid-state Li-metal batteries with composite electrolyte}

Because the Li-ion transmission efficiency and interface stability were improved by using this electrolyte, all-solid-state Li-metal batteries with $\mathrm{LiFePO}_{4}$ cathodes were assembled to evaluate the electrochemical performance of the composite electrolytes for practical applications. The main issue faced by the PEO-based electrolyte was the unsatisfactory oxidative stability on the cathode/electrolyte interface, which restricts their widespread application at voltages higher than $3.9 \mathrm{~V}$ [16,50,51]. Evaluating the leakage current during electrochemical floating has been 

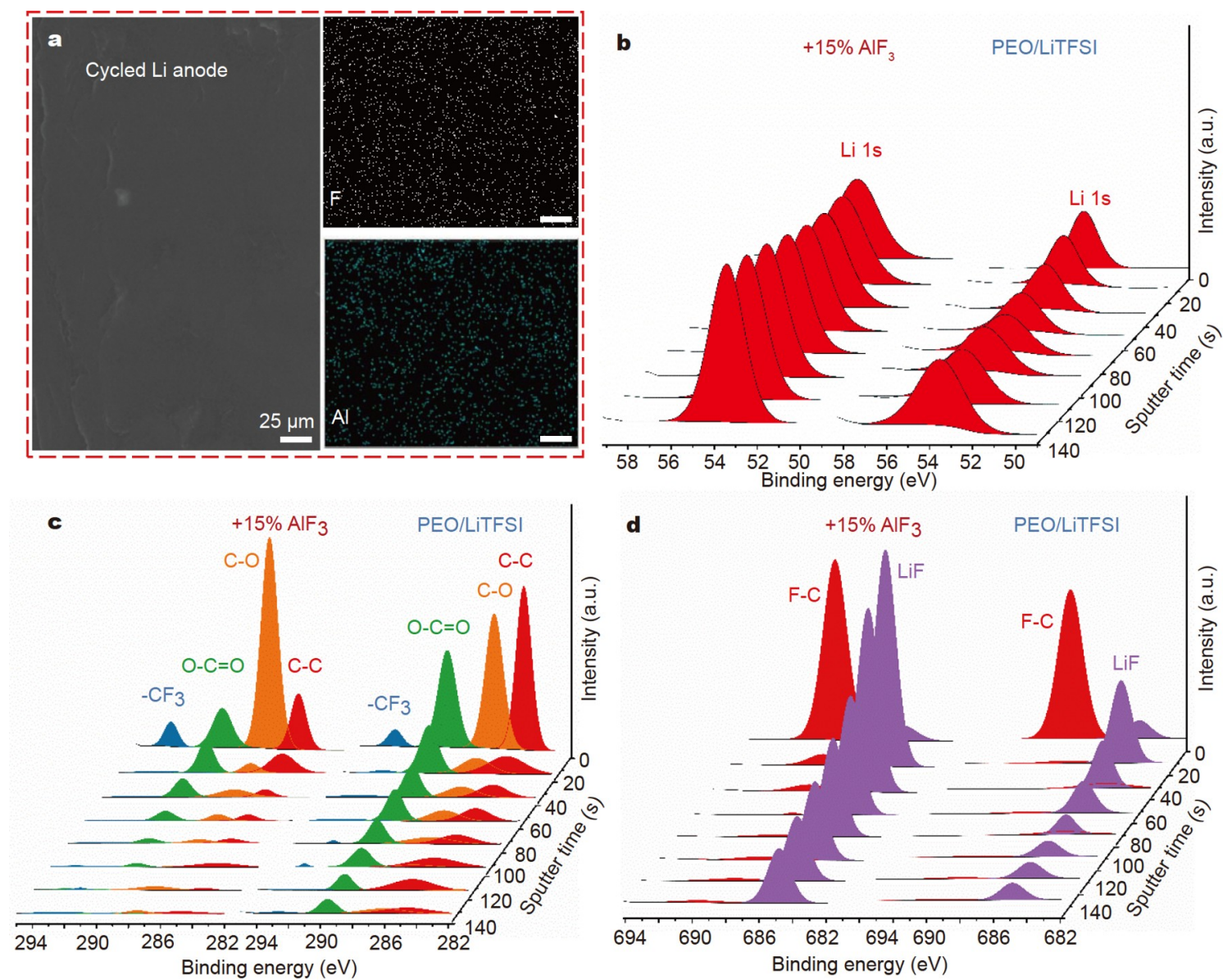

Figure 5 (a) Morphologies and EDS mapping of the Li metal anode after cycling. The high-resolution fitted (b) Li 1s, (c) C 1s, and (d) F 1s XPS depth (etching time) analysis of the cycled Li electrodes compared with those for pure PEO/LiTFSI and PEO/LiTFSI $+15 \% \mathrm{AlF}_{3}$ electrolytes.

identified as a good method for assessing antioxidation performance. The results of electrochemical floating, shown in Fig. 6a, demonstrated that the PEO/LiTFSI with the $\mathrm{AlF}_{3}$-modified electrolyte had a small leakage current at voltages as high as $4.2 \mathrm{~V}$. In contrast, the pure PEO/LiTFSI electrolyte had an smaller leakage current at $4.0 \mathrm{~V}$. Further, the as-assembled Li| $\mathrm{PEO} / \mathrm{LiTFSI}+15 \% \mathrm{AlF}_{3} \mid$ lithium-iron-phosphate (LFP) solidstate battery had a total resistance of $80 \Omega$, which was smaller than that of the PEO/LiTFSI electrolyte-based battery (Fig. S19). The improved oxidative stability of the composite electrolyte can be attributed to the strong interaction between the Lewis acid sites and TFSI $^{-}$anions, which could prevent the oxidation of the anion and enhance the electrochemical stability of the composite electrolyte.

To identify the fast-charging ability of the solid-state batteries, the rate performances are compared in Fig. 6b. The specific capacity of the solid battery with PEO/LiTFSI $+15 \% \mathrm{AlF}_{3}$ electrolytes was $146,143,138,126,114$, and $88 \mathrm{~mA} \mathrm{~h} \mathrm{~g}^{-1}$ at 0.1 , $0.2,0.3,0.5,1$, and $2 \mathrm{C}$, respectively, which are higher than those for the PEO/LiTFSI, especially at higher rates, benefiting from the higher Li-ion conductivity and smooth Li deposition. Further, as shown in Fig. $6 \mathrm{c}$, the PEO/LiTFSI $+15 \% \mathrm{AlF}_{3}$ composite electrolyte also had higher capacity retention $\left(105 \mathrm{~mA} \mathrm{~h} \mathrm{~g}^{-1}\right.$ and 92.1\% retention) and high Coulombic efficiency (higher than $98 \%$ ) for 150 cycles at $1 \mathrm{C}$ in the voltage range of $2.4-4.2 \mathrm{~V}$. Fig. $6 \mathrm{~d}$ presents the detailed selected voltage profiles of solidstate batteries with the two electrolytes. All of the voltage profiles exhibited flat and smooth voltage plateaus, representing the limited leakage current and electrochemical stability of the electrolyte and electrode interface. In addition, the battery with the composite electrolyte exhibited lower voltage hysteresis and higher Coulombic efficiency. In contrast, the cell with the PEO/ LiTFSI electrolyte could only be stably operated for less than 50 cycles. The Coulombic efficiency of the $150^{\text {th }}$ cycle was about $63.3 \%$, which was mainly induced by the uneven Li consumption, large interfacial resistance, and PEO decomposition. These features indicate that the as-prepared composite electrolyte, with improved ion transmission efficiency and stability of the cathode, solve two critical challenges for PEO-based electrolytes in practical applications.

\section{CONCLUSIONS}

In summary, we introduce a strong Lewis acid into the PEObased polymer electrolyte to improve both the ion transference number of composite electrolyte and interface stability of the $\mathrm{Li}$ metal/electrolyte. The $\mathrm{AlF}_{3}$ additive in the $\mathrm{PEO}$ matrix increased the amount of amorphous volume and free $\mathrm{Li}$ for enhancing $\mathrm{Li}$ ion conduction. The Lewis acid-base interaction between the $\mathrm{AlF}_{3}$ and $\mathrm{TFSI}^{-}$facilitated the dissociation of $\mathrm{Li}$ salts and immobilized the anions, resulting in sufficient Li ions transfer and homogeneous $\mathrm{Li}$ ion deposition. In addition, the in-situ generated LiF-rich interface during the initial cycling could inhibit the continuous side reactions between the metallic $\mathrm{Li}$ and PEO matrix and enhance the stability of the Li/PEO interface. 

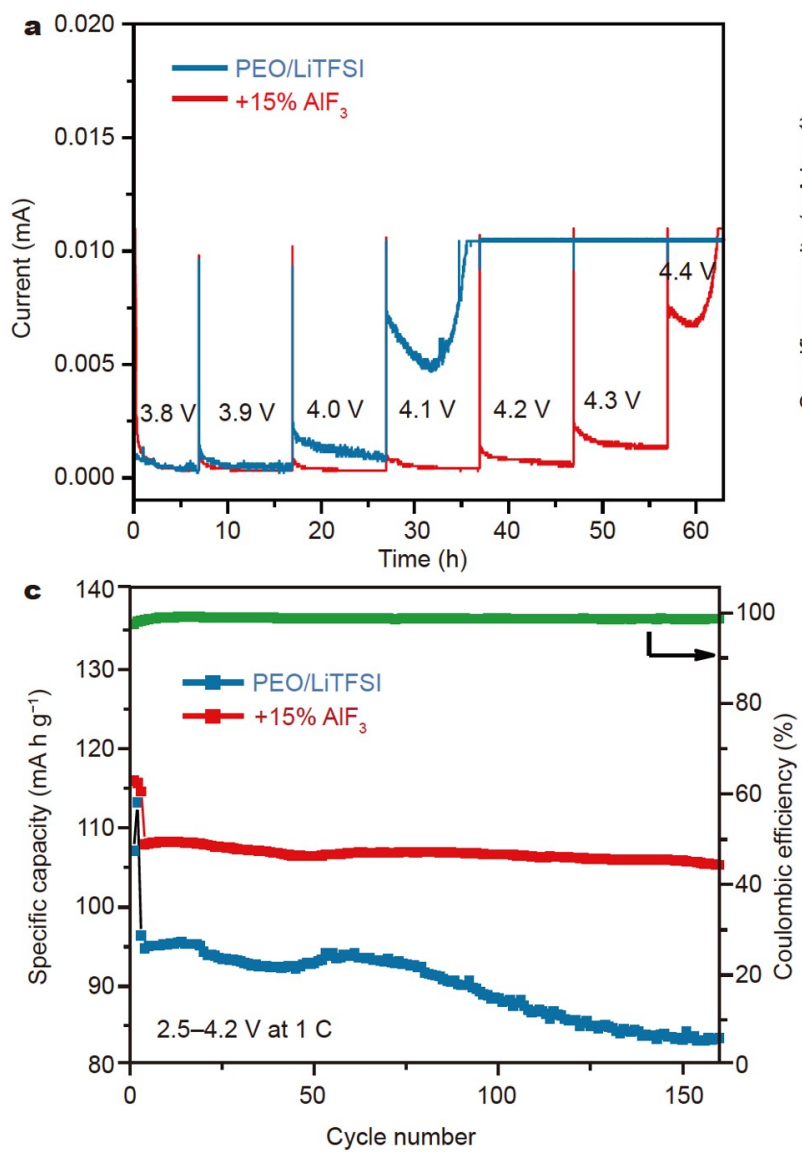
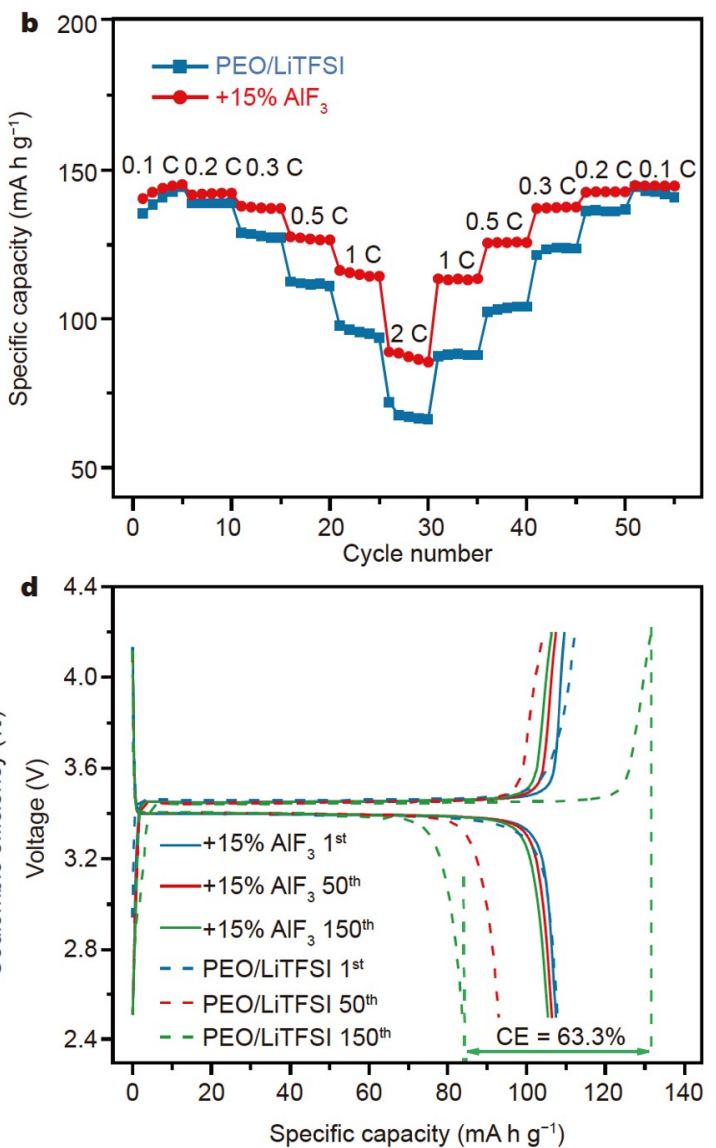

Figure 6 (a) Electrochemical floating analysis of the PEO/LiTFSI $+15 \% \mathrm{AlF}_{3}$ electrolyte and pure PEO/LiTFSI electrolyte using LFP cathodes. (b) Rate performances, (c) cycling performance, and (d) the charge/discharge curves of $\mathrm{Li}\left|\mathrm{PEO} / \mathrm{LiTFSI}+15 \% \mathrm{AlF}_{3}\right| \mathrm{LFP}$ and $\mathrm{Li}|\mathrm{PEO} / \mathrm{LiTFSI}| \mathrm{LFP}$ solid-state batteries from 0.1 to $2 \mathrm{C}$ at $60^{\circ} \mathrm{C}$.

Compared with the PEO/LiTFSI electrolyte, the composite electrolyte with $\mathrm{AlF}_{3}$ additive delivered enhanced ion conductivities by $190 \%$ and a higher ion transfer number (0.46). Benefited from our rational design, the $\mathrm{Li}$ symmetric cells demonstrated ultralong cycling stability over $3600 \mathrm{~h}$, and the solid-state LFP full cells displayed a stable cycling performance during the voltage range of $2.4-4.2 \mathrm{~V}$. This work provids an alternative strategy for high-performance composite electrolytes, as well as the practical application of all-solid-state Li-metal batteries.

\section{Received 11 October 2021; accepted 24 November 2021;} published online 10 January 2022

1 Oh P, Lee H, Park S, et al. Improvements to the overpotential of allsolid-state lithium-ion batteries during the past ten years. Adv Energy Mater, 2020, 10: 2000904

2 Zhao Q, Stalin S, Zhao CZ, et al. Designing solid-state electrolytes for safe, energy-dense batteries. Nat Rev Mater, 2020, 5: 229-252

3 Sun C, Liu J, Gong Y, et al. Recent advances in all-solid-state rechargeable lithium batteries. Nano Energy, 2017, 33: 363-386

4 Janek J, Zeier WG. A solid future for battery development. Nat Energy, 2016, 1: 1-4

5 Cheng J, Hou G, Sun Q, et al. A novel coral-like garnet for highperformance PEO-based all solid-state batteries. Sci China Mater, 2022, 65: $364-372$

6 Zhang T, Wang Y, Song T, et al. Ammonia, a switch for controlling high ionic conductivity in lithium borohydride ammoniates. Joule, 2018, 2: 1522-1533

7 Zhai $\mathrm{P}$, Liu L, Gu X, et al. Interface engineering for lithium metal anodes in liquid electrolyte. Adv Energy Mater, 2020, 10: 2001257

8 Zhang Q, Cao D, Ma Y, et al. Sulfide-based solid-state electrolytes: Synthesis, stability, and potential for all-solid-state batteries. Adv Mater, 2019, 31: 1901131

9 Asano T, Sakai A, Ouchi S, et al. Solid halide electrolytes with high lithium-ion conductivity for application in $4 \mathrm{~V}$ class bulk-type all-solidstate batteries. Adv Mater, 2018, 30: 1803075

10 Liu L, Lyu J, Mo J, et al. Flexible, high-voltage, ion-conducting composite membranes with $3 \mathrm{D}$ aramid nanofiber frameworks for stable allsolid-state lithium metal batteries. Sci China Mater, 2020, 63: 703-718

11 Lv F, Wang Z, Shi L, et al. Challenges and development of composite solid-state electrolytes for high-performance lithium ion batteries. J Power Sources, 2019, 441: 227175

12 Zheng Y, Yao Y, Ou J, et al. A review of composite solid-state electrolytes for lithium batteries: Fundamentals, key materials and advanced structures. Chem Soc Rev, 2020, 49: 8790-8839

13 Li S, Zhang SQ, Shen L, et al. Progress and perspective of ceramic/ polymer composite solid electrolytes for lithium batteries. Adv Sci, 2020, 7: 1903088

14 Wang W, Yi E, Fici AJ, et al. Lithium ion conducting poly(ethylene oxide)-based solid electrolytes containing active or passive ceramic nanoparticles. J Phys Chem C, 2017, 121: 2563-2573

15 Yue L, Ma J, Zhang J, et al. All solid-state polymer electrolytes for highperformance lithium ion batteries. Energy Storage Mater, 2016, 5: 139164

16 Wang C, Wang T, Wang L, et al. Differentiated lithium salt design for multilayered PEO electrolyte enables a high-voltage solid-state lithium metal battery. Adv Sci, 2019, 6: 1901036

17 Long L, Wang S, Xiao M, et al. Polymer electrolytes for lithium polymer batteries. J Mater Chem A, 2016, 4: 10038-10069

18 Xue Z, He D, Xie X. Poly(ethylene oxide)-based electrolytes for lithium- 
ion batteries. J Mater Chem A, 2015, 3: 19218-19253

19 Wan J, Xie J, Kong X, et al. Ultrathin, flexible, solid polymer composite electrolyte enabled with aligned nanoporous host for lithium batteries. Nat Nanotechnol, 2019, 14: 705-711

20 Zagórski J, López del Amo JM, Cordill MJ, et al. Garnet-polymer composite electrolytes: New insights on local Li-ion dynamics and electrodeposition stability with Li metal anodes. ACS Appl Energy Mater, 2019, 2: 1734-1746

21 Zhang Y, Zuo TT, Popovic J, et al. Towards better Li metal anodes: Challenges and strategies. Mater Today, 2020, 33: 56-74

22 Lai C, Shu C, Li W, et al. Stabilizing a lithium metal battery by an in situ $\mathrm{Li}_{2} \mathrm{~S}$-modified interfacial layer via amorphous-sulfide composite solid electrolyte. Nano Lett, 2020, 20: 8273-8281

23 Zhang J, Zhao N, Zhang M, et al. Flexible and ion-conducting membrane electrolytes for solid-state lithium batteries: Dispersion of garnet nanoparticles in insulating polyethylene oxide. Nano Energy, 2016, 28: $447-454$

24 Huo H, Chen Y, Luo J, et al. Rational design of hierarchical "ceramicin-polymer" and "polymer-in-ceramic" electrolytes for dendrite-free solid-state batteries. Adv Energy Mater, 2019, 9: 1804004

25 Christie AM, Lilley SJ, Staunton E, et al. Increasing the conductivity of crystalline polymer electrolytes. Nature, 2005, 433: 50-53

26 Wang C, Yang Y, Liu X, et al. Suppression of lithium dendrite formation by using LAGP-PEO (LiTFSI) composite solid electrolyte and lithium metal anode modified by PEO (LiTFSI) in all-solid-state lithium batteries. ACS Appl Mater Interfaces, 2017, 9: 13694-13702

27 Chen F, Yang D, Zha W, et al. Solid polymer electrolytes incorporating cubic $\mathrm{Li}_{7} \mathrm{La}_{3} \mathrm{Zr}_{2} \mathrm{O}_{12}$ for all-solid-state lithium rechargeable batteries. Electrochim Acta, 2017, 258: 1106-1114

28 Zhao CZ, Zhang XQ, Cheng XB, et al. An anion-immobilized composite electrolyte for dendrite-free lithium metal anodes. Proc Natl Acad Sci USA, 2017, 114: 11069-11074

29 Li Y, Zhou W, Chen X, et al. Mastering the interface for advanced allsolid-state lithium rechargeable batteries. Proc Natl Acad Sci USA, 2016, 113: 13313-13317

30 Renna LA, Blanc FG, Giordani V. Interface modification of lithium metal anode and solid-state electrolyte with gel electrolyte. J Electrochem Soc, 2020, 167: 070542

31 Ao X, Wang X, Tan J, et al. Nanocomposite with fast $\mathrm{Li}^{+}$conducting percolation network: Solid polymer electrolyte with $\mathrm{Li}^{+}$non-conducting filler. Nano Energy, 2021, 79: 105475-105485

32 Chen N, Dai Y, Xing Y, et al. Biomimetic ant-nest ionogel electrolyte boosts the performance of dendrite-free lithium batteries. Energy Environ Sci, 2017, 10: 1660-1667

33 Lu Y, Tikekar M, Mohanty R, et al. Stable cycling of lithium metal batteries using high transference number electrolytes. Adv Energy Mater, 2015, 5: 1402073

34 Sheng $\mathrm{O}$, Jin $\mathrm{C}$, Luo J, et al. $\mathrm{Mg}_{2} \mathrm{~B}_{2} \mathrm{O}_{5}$ nanowire enabled multifunctional solid-state electrolytes with high ionic conductivity, excellent mechanical properties, and flame-retardant performance. Nano Lett, 2018, 18: 3104-3112

35 Zhao Y, Wang L, Zhou Y, et al. Solid polymer electrolytes with high conductivity and transference number of $\mathrm{Li}$ ions for Li-based rechargeable batteries. Adv Sci, 2021, 8: 2003675

36 Tu Z, Choudhury S, Zachman MJ, et al. Fast ion transport at solid-solid interfaces in hybrid battery anodes. Nat Energy, 2018, 3: 310-316

37 Liu Y, Lin D, Yuen PY, et al. An artificial solid electrolyte interphase with high Li-ion conductivity, mechanical strength, and flexibility for stable lithium metal anodes. Adv Mater, 2017, 29: 1605531

38 Wang Z, Shen L, Deng S, et al. $10 \mu \mathrm{m}$-thick high-strength solid polymer electrolytes with excellent interface compatibility for flexible all-solidstate lithium-metal batteries. Adv Mater, 2021, 33: 2100353

39 Fang R, Xu B, Grundish NS, et al. $\mathrm{Li}_{2} \mathrm{~S}_{6}$-integrated PEO-based polymer electrolytes for all-solid-state lithium-metal batteries. Angew Chem, 2021, 133: 17842-17847

40 Santiago A, Judez X, Castillo J, et al. Improvement of lithium metal polymer batteries through a small dose of fluorinated salt. J Phys Chem Lett, 2020, 11: 6133-6138

41 Eshetu GG, Judez X, Li C, et al. Ultrahigh performance all solid-state lithium sulfur batteries: Salt anion's chemistry-induced anomalous synergistic effect. J Am Chem Soc, 2018, 140: 9921-9933

42 Wang $\mathrm{H}$, Lin $\mathrm{D}$, Liu $\mathrm{Y}$, et al. Ultrahigh-current density anodes with interconnected $\mathrm{Li}$ metal reservoir through overlithiation of mesoporous $\mathrm{AlF}_{3}$ framework. Sci Adv, 2017, 3: 1701301

43 Miao X, Di H, Ge X, et al. $\mathrm{AlF}_{3}$-modified anode-electrolyte interface for effective $\mathrm{Na}$ dendrites restriction in NaSICON-based solid-state electrolyte. Energy Storage Mater, 2020, 30: 170-178

44 Jones JP, Hennessy J, Billings KJ, et al. Communication-Atomic layer deposition of aluminum fluoride for lithium metal anodes. J Electrochem Soc, 2020, 167: 060502

45 Liu Q, Zhou D, Shanmukaraj D, et al. Self-healing Janus interfaces for high-performance LAGP-based lithium metal batteries. ACS Energy Lett, 2020, 5: 1456-1464

46 Liu Y, Yu P, Wu Y, et al. The DFT-ReaxFF hybrid reactive dynamics method with application to the reductive decomposition reaction of the TFSI and DOL electrolyte at a lithium-metal anode surface. J Phys Chem Lett, 2021, 12: 1300-1306

47 Chen J, Li Q, Pollard TP, et al. Electrolyte design for Li metal-free Li batteries. Mater Today, 2020, 39: 118-126

$48 \mathrm{Yu}$ Y, Zhang B, He YB, et al. Mechanisms of capacity degradation in reduced graphene oxide/ $\alpha-\mathrm{MnO}_{2}$ nanorod composite cathodes of $\mathrm{Li}$-air batteries. J Mater Chem A, 2013, 1: 1163-1170

49 Yu HL, Zhao JN, Ben LB, et al. Dendrite-free lithium deposition with self-aligned columnar structure in a carbonate-ether mixed electrolyte. ACS Energy Lett, 2017, 2: 1296-1302

50 Ma J, Liu Z, Chen B, et al. A strategy to make high voltage $\mathrm{LiCoO}_{2}$ compatible with polyethylene oxide electrolyte in all-solid-state lithium ion batteries. J Electrochem Soc, 2017, 164: A3454-A3461

51 Xu F, Deng S, Guo Q, et al. Quasi-ionic liquid enabling single-phase poly(vinylidene fluoride)-based polymer electrolytes for solid-state $\mathrm{LiNi}_{0.6} \mathrm{Co}_{0.2} \mathrm{Mn}_{0.2} \mathrm{O}_{2} \| \mathrm{Li}$ batteries with rigid-flexible coupling interphase. Small Methods, 2021, 5: 2100262

Acknowledgements This work was supported by the research fund of Shenzhen Science and Technology Innovation Committee (SGDX20201103093600003), the University of Macau, Macau SAR (MYRG2018-00079-IAPME and MYRG2019-00115-IAPME), the Science and Technology Development Fund, Macau SAR (0092/2019/A2, 0059/2018/ A2, and 009/2017/AMJ), the National Thousand Young Talent plan, and the National Natural Science Foundation of China (21875040 \& 21905051).

Author contributions Wang L, Hong G and Tang Y designed the research and wrote the manuscript. Hong $\mathrm{G}$ and Tang $\mathrm{Y}$ supervised the project and analyzed the data. Wang L, Zhong $\mathrm{Y}$, and Wen $\mathrm{Z}$ carried out the experiments and discussions. Li C, Zhao J, Ge M, Zhou P and Zhang Y analyzed the data and refined the manuscript. All authors contributed to the general discussion.

Conflict of interest The authors declare that they have no conflict of interest.

Supplementary information Experimental details and supporting data are available in the online version of the paper.

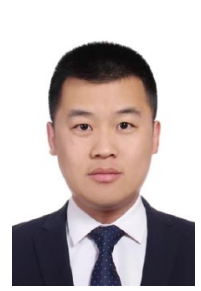

Litong Wang is currently a $\mathrm{PhD}$ candidate at the Institute of Applied Physics and Materials Engineering, University of Macau. His research interest focuses on the development of solid-state lithium metal batteries/fast charging electrode materials for electrochemical energy conversion and storage systems. 


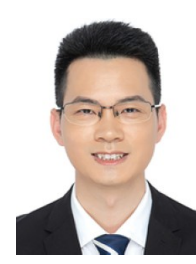

Yuxin Tang is a Professor at the College of Chemical Engineering, Fuzhou University. He obtained his BSc and MSc degrees from Nanjing University of Aeronautics and Astronautics in 2006 and 2009, respectively, and graduated from Nanyang Technological University (NTU) with a PhD degree in materials science (2013). After postdoctoral training in NTU, he joined the Institute of Applied Physics and Materials Engineering, University of Macau as an assistant professor in 2018. His research interests are the development of extreme energy storage devices and realtime electrochemical reaction monitoring techniques.

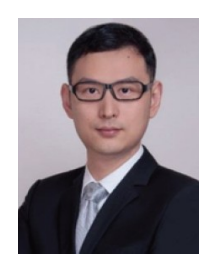

Guo Hong received his $\mathrm{PhD}$ degree in physical chemistry from Peking University in 2011. He was a postdoctoral researcher at the City University of Hong Kong from 2011 to 2013, and a postdoctoral researcher at Swiss Federal Institute of Technology, Switzerland from 2013 to 2016. He joined BTR New Energy Materials Inc., China as the deputy director of the research center in 2016. Currently, he is an assistant professor at the Institute of Applied Physics and Materials Engineering, and Faculty of Science and Technology, University of Macau. His research interests focus on low-dimensional materials, flexible devices, energy storage and conversion.
强路易斯酸诱导构筑高离子电导率和界面稳定的复 合电解质及其全固态锂金属电池

王立通 ${ }^{1}$, 仲云雷 ${ }^{1}$, 文㻇 锐 $^{1}$, 李朝威 ${ }^{1}$, 赵景新 ${ }^{1}$, 葛明政 ${ }^{1,4}$, 周鹏飞 ${ }^{1}$, 张炎炎 ${ }^{2}$, 汤育欣 ${ }^{2 *}$, 洪果 ${ }^{1,3^{*}}$

摘要 开发高性能固态聚合物电解质是高安全、高比能固态锂金属电 池的关键. 然而, 固态聚合物电解质的低离子电导率和不稳定的电解 质/电极界面阻碍了其广泛应用. 针对上述关键问题, 本文基于聚环氧 乙烷 $(\mathrm{PEO})$ 基电解质, 引入具有双功能的氟化铝 $\left(\mathrm{AlF}_{3}\right)$ 做为添加剂, 以 提高复合电解质的离子电导率和界面稳定性. 一方面, $\mathrm{AlF}_{3}$ 做为一种强 路易斯酸, 在和锂盐阴离子相互作用下可以促进锂盐的解离, 同时可以 固定阴离子, 从而提高锂离子传输效率; 另一方面, $\mathrm{AlF}_{3}$ 在电解质/电极 界面可以和锂金属原位反应生成富含 $\mathrm{LiF}$ 的界面层, 从而抑制锂金属的 不均匀沉积以及与 $\mathrm{PEO}$ 基体之间持续的副反应. 得益于我们的合理设 计, 匹配改性后电解质的 $\mathrm{Li} / \mathrm{Li}$ 对称电池可以稳定循环 $3600 \mathrm{~h}$ 以上. 同时, 在2.4-4.2 V电压区间内, 匹配复合电解质的全固态 $\mathrm{LiFePO}_{4}$ 全电池在 150 个循环之后库伦效率比没有 $\mathrm{AlF}_{3}$ 添加剂 $\mathrm{PEO}$ 基电解质大大提升 (98.4\% vs. 63.3\%)，匹配复合固态电解质的固态锂金属电池显示出优异 的界面稳定性和循环稳定性. 